CLINICAL PRACTICE

\title{
Drug-Use Evaluation Comparing Dexmedetomidine Use at 3 Health Authority Sites Relative to Manufacturer's Recommended Directions (DECODE Study)
}

\author{
Krystin Boyce, Edward C Dillon, Jerrold Perrott, Douglas L Malyuk, Vincent Mabasa, \\ Emma Attfield, Grant McCormack, and Sean Keenan
}

\section{INTRODUCTION}

$\mathrm{P}$ atients in the intensive care unit (ICU) are critically ill and often require external support such as mechanical ventilation to sustain life. Medications for sedation are routinely administered to control patients' level of consciousness and to reduce the anxiety that patients may experience in this setting. ${ }^{1}$ Historically, propofol and benzodiazepines (such as midazolam) have been the medications of choice for sedation in North America. ${ }^{2}$ However, the use of such medications has been associated with prolonged ventilation ${ }^{3}$ and the development of acute brain dysfunction, such as delirium or coma, ${ }^{4}$ which may increase the risk of death. ${ }^{5}$

Dexmedetomidine is an $\alpha_{2}$-receptor agonist that was approved for use as a sedative in Canada in 2010. Its mechanism of action is distinct from that of commonly used sedatives such as propofol and benzodiazepines, as it is not mediated by $\gamma$-aminobutyric acid; this makes it less prone to adverse effects such as respiratory depression. ${ }^{6}$ Dexmedetomidine is highly selective for the $\alpha_{2}$-adrenergic receptors in the locus ceruleus; it thereby reduces central sympathetic output, which increases inhibition of neurons with $\alpha_{2}$-agonist receptors. The activation of $\alpha_{2}$-adrenergic receptors in the dorsal horn of the spinal cord also modulates the release of substance $\mathrm{P}$ and produces analgesic effects. Currently in Canada, dexmedetomidine is indicated for sedation during treatment in an intensive care setting by continuous IV infusion for a maximum duration of $24 \mathrm{~h}$.

The drug manufacturer's product monograph specifies that for adult patients, dexmedetomidine is generally initiated with a loading infusion of up to $1 \mu \mathrm{g} / \mathrm{kg}$ over 10 to $20 \mathrm{~min}$, if needed; patients undergoing conversion from therapy with another sedative may not require a loading dose. It is suggested that adult patients will generally require a maintenance infusion of 0.2 to
$0.7 \mu \mathrm{g} / \mathrm{kg}$ per hour, with the understanding that the infusion rate should be adjusted ${ }^{7}$ to achieve the desired level of sedation.

Following IV administration, dexmedetomidine exhibits a rapid distribution phase, with a distribution half-life of about $6 \mathrm{~min}$, a terminal elimination half-life of about $2 \mathrm{~h}$, and a steadystate volume of distribution of about $118 \mathrm{~L}$. Clearance is estimated to be about $39 \mathrm{~L} / \mathrm{h} .{ }^{7}$ As such, further investigation may be warranted to determine whether the dosing used in practice is in accordance with that recommended by the manufacturer and, if any discrepancies do exist, whether they appear to contribute to measurable differences in patient outcomes.

This study was performed at 3 clinical sites located within a single health authority. The study was undertaken to provide insight into the use of dexmedetomidine for sedation in the ICU settings at each of the 3 sites and to compare these uses with usage as recommended in the product monograph. Developing this type of data for this particular drug may be useful for formulary review and consideration or for future medication-use evaluation projects, as the drug was not on the institution's formulary at the time of the study. Because of its nonformulary status, there was an element of unfamiliarity with dexmedetomidine use at the time the study was designed, and it was decided to use a cost-benefit approach to examine how the drug was used and potential ramifications, with comparison to directions for use as presented in the product monograph. The inclusion of 3 sites represented an attempt to increase the amount of data for the analysis (given restricted use of the drug at the time) and to reflect practice within the health authority as a whole, accounting for differences in perspectives and interpretations of recommended guidelines for use and prescribing variability among individual practitioners. 


\section{Objectives}

The primary objective of this study was to compare the use of dexmedetomidine at 3 sites within the Fraser Health Authority, British Columbia, with the usage directions recommended by the manufacturer. In particular, the following data were collected and reviewed: duration of therapy, use and number of bolus doses, drug infusion rates (specifically initial, lowest, highest, and weighted infusion rates), and total amounts of drug received daily.

The secondary objectives of the study were chosen to characterize the study population, the drug's effectiveness, and the drug's safety profile during the study. In particular, efficacyrelated secondary outcomes were patient characteristics (age, sex, weight); admission diagnosis (medical, surgical, or trauma); prior use of sedatives, including class of drug given, before initiation of dexmedetomidine; time (in hours) on mechanical ventilation for each patient while receiving dexmedetomidine; and percentage of documented sedation scores (according to Richmond Agitation Sedation Scale [RASS $]^{1}$ ) within the target range (i.e., between -1 and +1 ) during dexmedetomidine treatment. Safety-related secondary outcomes were incidence of delirium (documented according to the Intensive Care Delirium Screening Checklist ${ }^{1}$ ); incidence of serious adverse events, including (but not limited to) bradycardia (defined as heart rate $<40$ beats $/ \mathrm{min}$ or $>30 \%$ decline from baseline heart rate before drug administration); incidence of hypotension (systolic blood pressure $<80 \mathrm{~mm} \mathrm{Hg}$ or diastolic blood pressure $<50 \mathrm{~mm} \mathrm{Hg}$ or $>20 \%$ decrease from baseline mean arterial pressure before drug administration) during dexmedetomidine therapy; incidence of anaphylaxis or any other serious adverse effects associated with dexmedetomidine treatment and necessitating intervention or discontinuation of therapy; and total cost of dexmedetomidine per patient.

\section{METHODS}

This multicentre chart review was approved by the Fraser Health Research Ethics Board. The 3 study sites were Burnaby Hospital, a 295-bed acute care community hospital in Burnaby; the Royal Columbian Hospital, a 390-bed tertiary care trauma centre in New Westminster; and Surrey Memorial Hospital, a tertiary care centre in Surrey that had 499 beds at the time of study completion.

Following receipt of ethics approval, a list of patients who had been treated with dexmedetomidine in the ICU between January 1, 2011, and November 30, 2012, at each of the 3 sites was generated by the Pharmacy Department's computer system. Patient records were scanned by the electronic medical record system to ensure that patients met the following inclusion criteria: adult patients (18 years of age or older) with admission to the ICU at 1 of the 3 specified sites, and receipt of dexmedeto- midine for sedation. Data were collected and recorded by the primary author (K.B.) and a research assistant (E.A.).

The nature of the study was one of "quality improvement" for the use of dexmedetomidine in the sedation of patients in the ICU, and patient consent was therefore not required.

For each patient who met the inclusion criteria, the medical chart was reviewed for the duration of dexmedetomidine treatment (to a maximum of 30 days) and for up to 5 days after treatment discontinuation. Data were collected for each patient according to the variables listed in the "Objectives" section (above).

The potential maximum cost of dexmedetomidine was estimated on the basis of patient weight and the recommended maximum dose of $0.7 \mu \mathrm{g} / \mathrm{kg}$ per hour for $24 \mathrm{~h}$. The actual cost of drug used was calculated from the amounts given, accounting for partial vials opened and wastage and based on the cost of dexmedetomidine at the time of the study ( $\$ 41.67$ for a 200- $\mu$ g vial).

\section{Statistical Analysis}

Patient characteristics, prior sedative use, and adverse effect rates were analyzed by descriptive statistics. Dexmedetomidine parameters are expressed as means with standard deviations (SDs). The data are presented by individual site and combined for all 3 sites.

\section{RESULTS}

In total, 57 patients were identified as meeting the inclusion criteria over the 23-month study period. Of these, 7 patients received dexmedetomidine at Burnaby Hospital, 32 patients at the Royal Columbian Hospital, and the remaining 18 at Surrey Memorial Hospital. Patient demographic and baseline clinical characteristics are presented in Table 1.

\section{Primary Outcomes}

The duration of therapy deviated from the maximum recommended duration $(24 \mathrm{~h})$, with mean duration ranging from $19.7 \mathrm{~h}$ at Burnaby Hospital to $43.1 \mathrm{~h}$ at Surrey Memorial Hospital (Table 2); the mean duration of therapy across the 3 sites was $28.0 \mathrm{~h}$ (SD 17.6 h). The frequency of use of a bolus dose varied among sites, but when such doses were given, they followed the manufacturer's recommendation $(1 \mu \mathrm{g} / \mathrm{kg}$ over 10-20 min). Other infusion parameters, including minimum rate $(0.25 \pm 0.11 \mu \mathrm{g} / \mathrm{kg}$ per hour $)$, maximum rate $(0.64 \pm 0.21$ $\mu \mathrm{g} / \mathrm{kg}$ per hour $)$, and average weighted infusion rate $(0.51 \pm 0.16$ $\mu \mathrm{g} / \mathrm{kg}$ per hour) complied with those recommended for the maintenance of sedation by the product monograph. Other details regarding infusion parameters are presented in Table 2. 
Table 1. Demographic Characteristics of Patients Treated at 3 Sites

\begin{tabular}{|c|c|c|c|c|}
\hline \multirow[b]{2}{*}{ Characteristic } & \multicolumn{4}{|c|}{ Site; No. (\%) of Patients or Mean \pm SD } \\
\hline & $\begin{array}{l}\text { All sites } \\
(n=57)\end{array}$ & $\begin{array}{c}\text { Burnaby } \\
(n=7)\end{array}$ & $\begin{array}{c}\text { Royal } \\
\text { Columbian } \\
(n=32)\end{array}$ & $\begin{array}{c}\text { Surrey } \\
\text { Memorial } \\
(n=18)\end{array}$ \\
\hline Sex, male & $39(68)$ & $4(57)$ & $23(72)$ & $12(67)$ \\
\hline Age (years) & $45 \pm 19$ & $50 \pm 21$ & $44 \pm 18$ & $60 \pm 14$ \\
\hline Weight (kg) & $80 \pm 27$ & $93 \pm 41$ & $85 \pm 23$ & $86 \pm 21$ \\
\hline \multicolumn{5}{|l|}{ Reason for admission } \\
\hline Medical & $42(74)$ & $7(100)$ & $18(56)$ & $18(100)$ \\
\hline Trauma & $15(26)$ & 0 & $14(44)$ & 0 \\
\hline \multicolumn{5}{|l|}{ Vital signs at baseline } \\
\hline Heart rate (beats/min) & $93 \pm 19$ & $97 \pm 11$ & $92 \pm 20$ & $97 \pm 15$ \\
\hline Mean arterial pressure $(\mathrm{mm} \mathrm{Hg})$ & $86 \pm 15$ & $83 \pm 98$ & $7 \pm 16$ & $88 \pm 19$ \\
\hline \multicolumn{5}{|c|}{$\begin{array}{l}\text { Previous sedative or antipsychotic } \\
\text { administered }\end{array}$} \\
\hline Benzodiazepine & $53(93)$ & $6(86)$ & $32(100)$ & $15(83)$ \\
\hline Propofol & $34(60)$ & $1(14)$ & $24(75)$ & $9(50)$ \\
\hline Antipsychotic & $51(89)$ & $3(43)$ & $26(81)$ & $6(33)$ \\
\hline Baseline RASS score & $-0.94 \pm 2.91$ & $-1.33 \pm 2.16$ & $-0.81 \pm 3.23$ & $-0.88 \pm 2.64$ \\
\hline
\end{tabular}

Table 2. Details of Dexmedetomidine Administration

\begin{tabular}{|c|c|c|c|c|}
\hline \multirow[b]{2}{*}{ Variable } & \multicolumn{4}{|c|}{ Site; Mean \pm SD* } \\
\hline & $\begin{array}{l}\text { All sites } \\
(n=57)\end{array}$ & $\begin{array}{c}\text { Burnaby } \\
(n=7)\end{array}$ & $\begin{array}{l}\text { Royal Columbian } \\
(n=32)\end{array}$ & $\begin{array}{l}\text { Surrey Memorial } \\
(n=18)\end{array}$ \\
\hline \multicolumn{5}{|l|}{ Bolus dose } \\
\hline No. (\%) of patients & $24(42)$ & 0 & $17(53)$ & $6(33)$ \\
\hline Dose given $(\mu \mathrm{g} / \mathrm{kg})$ & $1 \pm 1$ & 0 & $0.93 \pm 0.23$ & $1 \pm 0$ \\
\hline \multicolumn{5}{|l|}{ Infusion rate ( $\mu \mathrm{g} / \mathrm{kg}$ per hour) } \\
\hline Initial rate & $10.37 \pm 0.17$ & $0.40 \pm 0.00$ & $0.40 \pm 0.19$ & $0.29 \pm 0.14$ \\
\hline Minimum rate & $10.25 \pm 0.11$ & $0.30 \pm 0.12$ & $0.27 \pm 0.13$ & $0.21 \pm 0.02$ \\
\hline Maximum rate & $10.64 \pm 0.21$ & $0.79 \pm 0.20$ & $0.66 \pm 0.20$ & $0.61 \pm 0.21$ \\
\hline Average weighted infusion rate & $10.51 \pm 0.16$ & $0.51 \pm 0.13$ & $0.54 \pm 0.16$ & $0.45 \pm 0.15$ \\
\hline \multicolumn{5}{|l|}{ Duration of therapy (h) } \\
\hline Dexmedetomidine therapy & $28.0 \pm 17.61$ & $9.7 \pm 13.32$ & $9.8 \pm 18.14$ & $3.1 \pm 20.4$ \\
\hline Intubation while receiving dexmedetomidine & $19.4 \pm 18.31$ & $0.7 \pm 11.62$ & $1.3 \pm 19.12$ & $8.9 \pm 28.6$ \\
\hline \multicolumn{5}{|l|}{ Cost-related factors } \\
\hline Total amount of drug received $(\mu \mathrm{g})$ & $1490.1 \pm 212.38$ & $96.8 \pm 769.91$ & $494.4 \pm 1136$ & $1603.2 \pm 837.9$ \\
\hline Total cost of drug received $(\$)$ & $303.22 \pm 212.26$ & $186.85 \pm 160.40$ & $311.36 \pm 236.68$ & $334.02 \pm 174.57$ \\
\hline
\end{tabular}

$\mathrm{SD}=$ standard deviation.

*Except where indicated otherwise.

\section{Secondary Outcomes}

Results for secondary outcomes, including duration of ventilation, RASS scores within target range, and incidence of adverse effects, are presented here according to efficacy and safety. Data for prior sedative use are presented in Table 1.

\section{Effectiveness}

Before initiation of dexmedetomidine therapy, a baseline RASS score was reported for 54 (95\%) of the patients (Figure 1), and for 42 (78\%) of these patients, the RASS score was outside the target range of -1 to +1 . Of these 42 patients with RASS score outside the target range before initiation of dexmedetomidine, $31(74 \%)$ patients reached target RASS during dexmedetomidine therapy (Table 3).

Baseline delirium scores were recorded for 24 patients (42\%). Of the 13 patients with a positive delirium score at baseline (Figure 2), 6 (46\%) had resolution of delirium, as indicated by negative delirium scores, while receiving dexmedetomidine therapy (Table 4). 


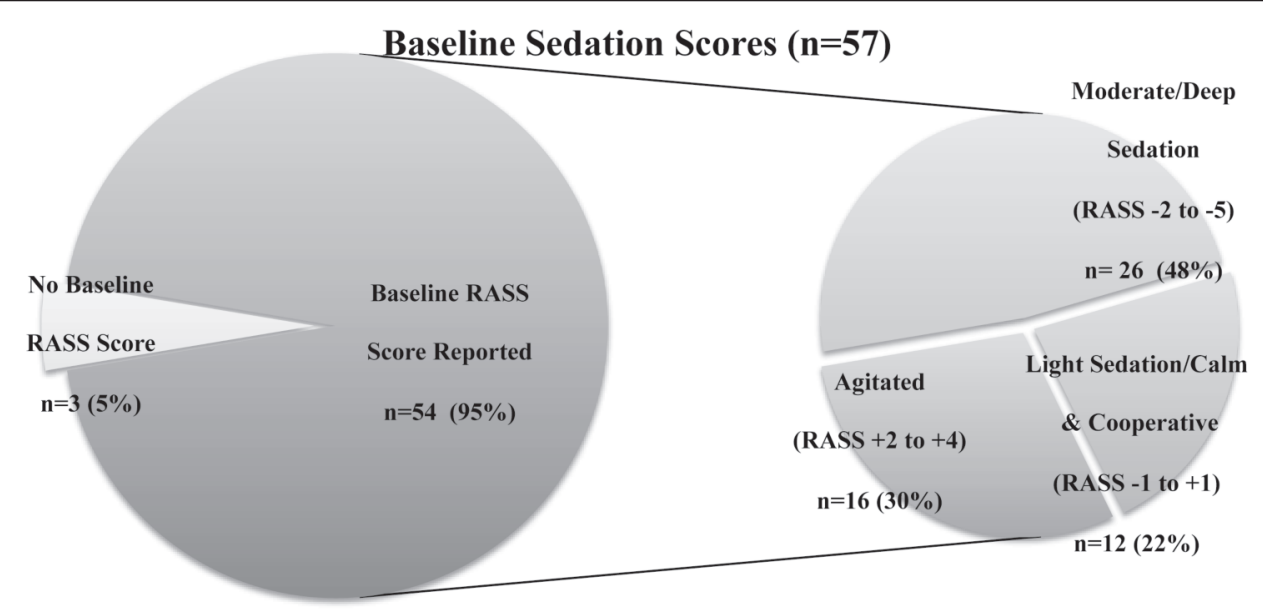

Figure 1. Baseline sedation scores before dexmedetomidine therapy.

Table 3. Sedation Scores at 3 Sites before and during Dexmedetomidine Treatment

\begin{tabular}{|c|c|c|c|c|}
\hline Variable & $\begin{array}{l}\text { All sites } \\
(n=57)\end{array}$ & $\begin{array}{c}\text { Burnaby } \\
(n=7)\end{array}$ & $\begin{array}{l}\text { Royal Columbian } \\
(n=32)\end{array}$ & $\begin{array}{l}\text { Surrey Memorial } \\
\qquad(n=18)\end{array}$ \\
\hline Duration of therapy $(\mathrm{h})($ mean \pm SD) & $28.0 \pm 17.61$ & $9.7 \pm 13.32$ & $9.8 \pm 18.14$ & $3.1 \pm 20.4$ \\
\hline $\begin{array}{l}\text { No. (\%) of patients with any baseline } \\
\text { RASS score }\end{array}$ & $54(95)$ & $6(86)$ & $31(97)$ & $17(94)$ \\
\hline $\begin{array}{l}\text { Moderate to deep sedation } \\
\text { (RASS }-5 \text { to }-2 \text { ) }\end{array}$ & $26(48)$ & $2(33)$ & $15(48)$ & $9(53)$ \\
\hline $\begin{array}{l}\text { Light sedation, calm and cooperative } \\
\text { (RASS }-1 \text { to }+1)\end{array}$ & $12(22)$ & $4(67)$ & $4(13)$ & $4(24)$ \\
\hline Agitated (RASS +2 to +4$)$ & $16(30)$ & 0 & $12(39)$ & $4(24)$ \\
\hline Baseline RASS score (mean \pm SD) & $-0.94 \pm 2.91$ & $-51.33 \pm 2.16$ & $-50.81 \pm 3.23$ & $-50.88 \pm 2.64$ \\
\hline $\begin{array}{l}\text { No. (\%) with } \geq 1 \text { RASS score reported } \\
\text { while on dex }\end{array}$ & $50(88)$ & $6(86)$ & $28(88)$ & $17(94)$ \\
\hline No. of RASS scores per patient (mean \pm SD) & $6.6 \pm 5.1$ & $2.2 \pm 1.5$ & $7 \pm 5.4$ & $7.4 \pm 4.6$ \\
\hline $\begin{array}{l}\text { No. of RASS scores between }-1 \text { and }+1 \\
\text { while on dex (mean } \pm \text { SD) }\end{array}$ & $3.0 \pm 2.6$ & $2.2 \pm 1.5$ & $2.6 \pm 2.7$ & $4.1 \pm 2.6$ \\
\hline $\begin{array}{l}\% \text { of RASS scores between }-1 \text { and }+1 \\
\text { while on dex therapy (mean } \pm \text { SD) }\end{array}$ & $46.1 \pm 51.5$ & 100 & $42.4 \pm 35.7$ & $61.9 \pm 29.8$ \\
\hline $\begin{array}{l}\text { No. (\%) of patients with baseline RASS } \\
\text { below }-1 \text { or above }+1 \text { and improvement } \\
\text { on dex therapy }\end{array}$ & $31 / 42(74)$ & $1 / 2(50)$ & $18 / 27(67)$ & $12 / 13(92)$ \\
\hline
\end{tabular}

\section{Safety}

Bradycardia and hypotension were the only documented adverse effects during the treatment courses. Overall, 13 (23\%) of the 57 patients had one or more episodes of bradycardia (Figure 3), and 31 (54\%) patients had one or more episodes of hypotension (Figure 4).

\section{Cost}

The actual cost of the drug used amounted to about 25\% of the potential maximum cost based on patients' body weight, recommended dosage, and drug cost at the time of the study (Table 5).

\section{DISCUSSION}

This chart review analyzed the use of dexmedetomidine for sedation in adult patients in the ICUs of 3 acute care hospitals in a single health authority.

The dosages and infusion parameters observed fell within the guidelines recommended in the product monograph, but the duration of use varied substantially across the 3 sites. The mean duration of therapy $(28.0 \mathrm{~h})$ was longer than that recommended by the manufacturer $(24 \mathrm{~h})$, although recent literature has supported the safety of an extended duration of dexmedetomidine use (i.e., beyond 24 h). ${ }^{6}$ Similar to previously published reports, ${ }^{8-10}$ there was variation in the duration of dexmedetomidine therapy, both among sites and relative to the manufacturer's 


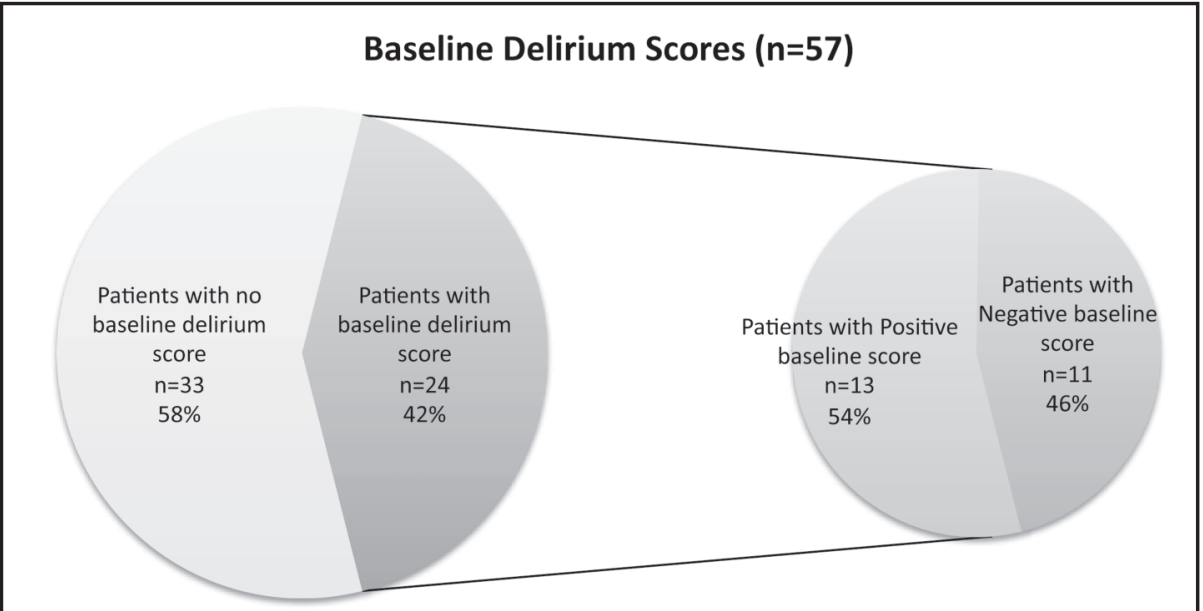

Figure 2. Baseline delirium scores before dexmedetomidine therapy.

Table 4. Delirium Scores* at 3 Sites before and during Dexmedetomidine Treatment

\begin{tabular}{|c|c|c|c|c|}
\hline Variable & $\begin{array}{l}\text { All sites } \\
(n=57)\end{array}$ & $\begin{array}{c}\text { Burnaby } \\
(n=7)\end{array}$ & $\begin{array}{l}\text { Royal Columbian } \\
(n=32)\end{array}$ & $\begin{array}{l}\text { Surrey Memorial } \\
\quad(n=18)\end{array}$ \\
\hline Duration of therapy $(\mathrm{h})($ mean \pm SD) & $28.0 \pm 17.61$ & $9.7 \pm 13.32$ & $9.8 \pm 18.14$ & $3.1 \pm 20.4$ \\
\hline $\begin{array}{l}\text { No. (\%) of patients with any baseline } \\
\text { delirium score }\end{array}$ & $24(42)$ & 0 & $16(50)$ & $10(56)$ \\
\hline With "positive" baseline score $(\geq 4)$ & $13(54)$ & NA & $8(50)$ & $6(60)$ \\
\hline Range of reported scores & 0 to 8 & NA & 0 to 8 & 0 to 8 \\
\hline $\begin{array}{l}\text { No. (\%) of patients with } \geq 1 \text { delirium } \\
\text { score reported while on dex }\end{array}$ & $27(47)$ & $2(29)$ & $17(53)$ & $12(67)$ \\
\hline $\begin{array}{l}\text { No. (\%) with no "positive" scores } \\
\text { while on dex }\end{array}$ & $13(48)$ & $2(100)$ & $6(35)$ & $7(58)$ \\
\hline Range of reported scores & 0 to 8 & 0 & 0 to 8 & 0 to 8 \\
\hline $\begin{array}{l}\text { No. of delirium scores per patient } \\
\text { (mean } \pm \text { SD) }\end{array}$ & $2.2 \pm 2.5$ & 1 & $1.4 \pm 0.5$ & $3.7 \pm 3.6$ \\
\hline $\begin{array}{l}\text { No. of scores indicating delirium } \\
\text { per patient (mean } \pm \text { SD) }\end{array}$ & $1.8 \pm 1.6$ & 0 & $1.4 \pm 0.5$ & $2.8 \pm 2.7$ \\
\hline $\begin{array}{l}\% \text { of scores indicating delirium while } \\
\text { on dex (mean } \pm \text { SD) }\end{array}$ & $46.9 \pm 48.2$ & 0 & $61.8 \pm 48.5$ & $33.7 \pm 44.5$ \\
\hline $\begin{array}{l}\text { No. (\%) of patients with "positive" } \\
\text { score at baseline and improvement } \\
\text { on dex therapy }\end{array}$ & $6 / 13(46)$ & NA & $1 / 8(13)$ & $5 / 6(83)$ \\
\hline
\end{tabular}

recommendation. One plausible explanation may be interprofessional collaboration between physicians and pharmacists in the study hospitals and interactions with practitioners in the United States, where dexmedetomidine therapy is often extended to 5-7 days or longer. ${ }^{2}$ It may be reasonable to assume that collaboration and discussion among practitioners is more common at the Royal Columbian Hospital and Surrey Memorial Hospital (because some practitioners work at both of these sites), which might result in greater similarity in dosing and infusion parameters between these 2 sites (with differences relative to Burnaby Hospital).
The data collected provide practical insight into the use of dexmedetomidine in the Lower Mainland of British Columbia, which may be applicable as guidance to direct future dosing as dexmedetomidine becomes more widely used in this health authority.

Consistent with the literature, bradycardia and hypotension were the only documented adverse effects during dexmedetomidine therapy, but details regarding the incidence and duration of adverse events may have been affected by reporting bias or incomplete documentation by clinical staff. However, the incidence of such events observed in this study population 


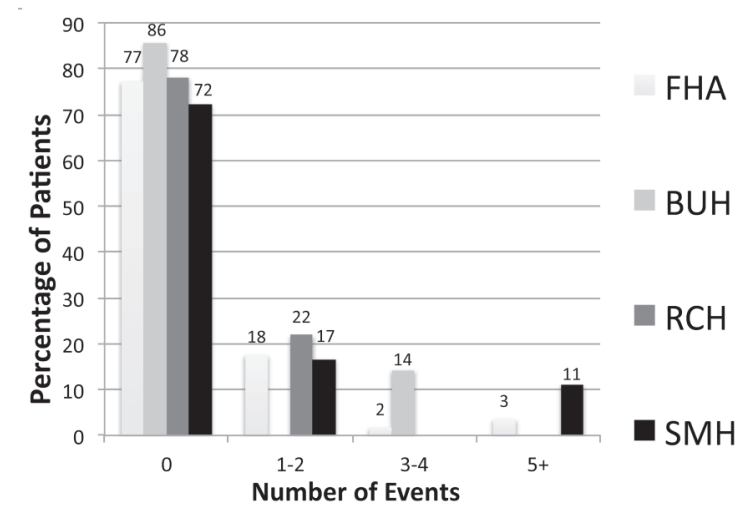

Figure 3. Incidence of bradycardia at 3 sites (individually and combined) during dexmedetomidine therapy. $\mathrm{FHA}=$ Fraser Health Authority, BUH = Burnaby Hospital, $\mathrm{RCH}=$ Royal Columbian Hospital, SMH = Surrey Memorial Hospital.

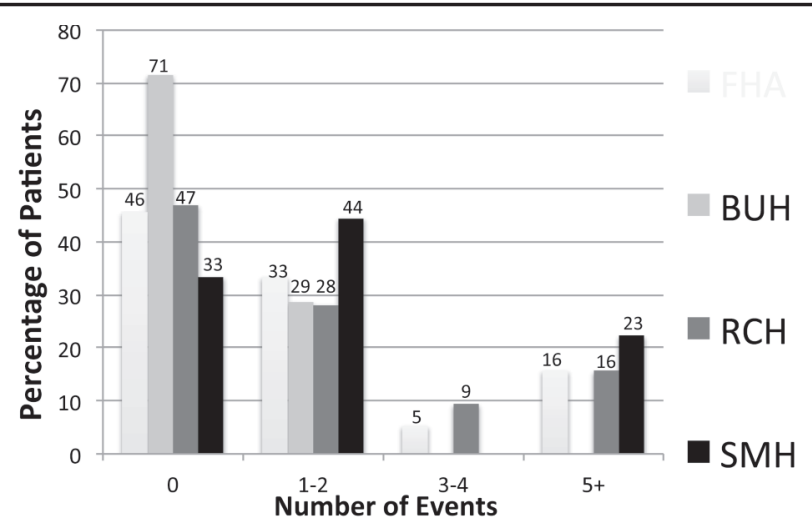

Figure 4. Incidence of hypotension at 3 sites (individually and combined) during dexmedetomidine therapy. $\mathrm{FHA}=$ Fraser Health Authority, BUH $=$ Burnaby Hospital, $\mathrm{RCH}=$ Royal Columbian Hospital, SMH = Surrey Memorial Hospital.

Table 5. Cost Details for Dexmedetomidine Treatment at 3 Sites

\begin{tabular}{lcccc} 
Variable & All sites & Burnaby & Royal Columbian & Surrey Memorial \\
\hline No. of patients & 57 & 7 & 32 & 18 \\
Total estimated cost $(\$)^{*}$ & 71746.08 & 10928.40 & 45785.04 & 25961.04 \\
Actual total cost $(\$)$ & 17375.67 & 1333.44 & 10000.08 & 6042.15 \\
\% of estimated cost spent & 24.2 & 12.2 & 21.8 & 23.3 \\
\hline *Based on patient weight, dosing at $0.7 \mu \mathrm{g} / \mathrm{kg}$ per hour for $24 \mathrm{~h}$, and cost of \$41.67 per 200- $\mu \mathrm{g}$ vial of the drug.
\end{tabular}

seemed consistent with previous reports, in which incidence ranged from $20 \%$ to $40 \%$ of patients. ${ }^{8,9}$

A cost analysis was completed to compare the estimated cost (based on patient weight, maximum recommended dosing, and drug cost at the time of the study) and the actual cost of dexmedetomidine used. Interestingly, although duration of therapy extended beyond the recommended $24 \mathrm{~h}$, the actual cost of dexmedetomidine used remained substantially below the estimated cost. Previous studies have supported dexmedetomidine as a cost-effective therapeutic alternative for sedation, given its ability to reduce ventilation time, delirium, and other factors contributing to an extended ICU stay. ${ }^{3-5}$ The results of the current study seem to indicate that dexmedetomidine was primarily used in the Fraser Health Authority as per the manufacturer's recommended directions. The data also indicate that this drug may cause adverse effects, such as hypotension and bradycardia, as noted by the manufacturer.

In this study, sites that used more bolus doses and longer durations of therapy seemed to have higher incidence of bradycardia and hypotension. Previous researchers have found correlations between the use of bolus doses and longer duration of therapy and the incidence of bradycardia and hypotension. ${ }^{10}$ Further research may be able to determine more details on the relationship between dexmedetomidine dosing and hemodynamic instability. In the current study, no other adverse effects, such as respiratory depression or anaphylaxis, were documented during dexmedetomidine therapy.

Although the data collected seemed to support an improvement in RASS scores (to within the target range) with dexmedetomidine therapy, the documentation of RASS and delirium scores in patients' charts was highly variable. Unfortunately, scoring and documentation of scores depends on charting by the health care team. Fewer than half of the patients had a baseline delirium score recorded in the chart, and more than half had no delirium scores documented while they were receiving dexmedetomidine therapy. Incomplete documentation makes it difficult to draw conclusions about the effect of dexmedetomidine on sedation and delirium scores and is a limitation of this and other retrospective studies.

Given the retrospective nature of this study, it was also difficult to draw conclusions about the effects of dexmedetomidine on patient outcomes such as sedation and delirium levels, as it was not possible to control for other confounders. In particular, it was difficult to determine whether RASS scores had improved because patients' illnesses and acuity levels had improved or whether the effects observed were due to the dexmedetomidine therapy. Further research, in the form of a prospective, randomized controlled trial (RCT), would better control for confounders and have greater ability to show an effect directly related to the dexmedetomidine treatment. Doses higher than those recom- 
mended by the manufacturer (up to $1.4 \mu \mathrm{g} / \mathrm{kg}$ per hour) have been used safely in RCTs, and the median dose used in one such trial was about $0.9 \mu \mathrm{g} / \mathrm{kg}$ per hour, achieving the target RASS in that study of -3 to 0 , with median duration of use of 42 h. ${ }^{11}$ Building on the literature and with access to more resources, we hope to show a patient-care benefit from these parameters of dexmedetomidine use in our patient population. We also hope to conduct future studies comparing the use of various sedative agents and to investigate the dosing, efficacy, and safety of dexmedetomidine when used in ways that differ from the manufacturer's directions for use.

All patients who received dexmedetomidine also received one or more prior sedative medications, most commonly midazolam or propofol. As dexmedetomidine was a nonformulary medication at the time of the study, patients had to "fail" or be deemed ineligible for sedation with formulary alternatives before dexmedetomidine could be initiated. The regimen used to discontinue the previous sedative and initiate dexmedetomidine was variable, and some patients were treated with multiple or concomitant sedatives. The variability in dexmedetomidine administration might also have affected certain outcomes, such as time to extubation, duration of therapy, and sedation and delirium scores.

Although all patients who received dexmedetomidine during the defined study period were included in the overall analysis, the number of patients who met the inclusion criteria was limited, perhaps because the drug was a nonformulary medication at the time of the chart review. In addition, comparing patients across the 3 sites might be misleading, as hospital services differ.

The limitations of this study pertain to its retrospective design and the inability to control for confounders, as well as lack of documentation, all of which made it difficult to draw firm conclusions about dexmedetomidine use at the study sites. Although the RASS and delirium scoring tools have been well validated and have acceptable rates of interpractitioner variability, ${ }^{1}$ reporting of these scores may vary among nurses, as both scoring systems have subjective components for assessing a patient. These variations might have modestly affected the results, given the small number of reported scores, and attempting to generalize these findings to a larger patient population may be inappropriate. Interestingly, the fact that almost $50 \%$ of patients had a low baseline RASS score (between -5 and -2 , indicating moderate or deep sedation) may have contributed to the lack of documented delirium scores: for patients with RASS score between -5 and -4 , delirium scoring is deferred, according to critical care practice guidelines. ${ }^{1}$

We highly recommend more consistent use of delirium scoring systems and documentation of the resulting scores, given that only 24 of the patients across the 3 sites had documentation of delirium scores at baseline. In addition, it is likely that RASS documentation could also be improved, to a minimum of at least one entry per shift.

\section{CONCLUSIONS}

This chart review provided details on the use of dexmedetomidine at 3 acute care sites in the same health authority. The infusion parameters complied with the recommended directions in the product monograph. Deviations from recommendations were observed in terms of administration of bolus doses and duration of therapy.

Most patients experienced adequate sedation while receiving dexmedetomidine, with $46 \%$ of documented RASS scores being within the target range $(-1$ to +1$)$. Bradycardia and hypotension were the only documented adverse effects, appearing in about $20 \%$ to $50 \%$ of patients.

Dexmedetomidine appeared to be an effective and safe therapeutic alternative for the sedation of adult patients at $3 \mathrm{ICU}$ sites within the Fraser Health Authority, based on its evaluated use at Burnaby Hospital, the Royal Columbian Hospital, and Surrey Memorial Hospital.

\section{References}

1. Barr J, Gilles LF, Puntillo K, Ely EW, Gélinas C, Dasta JF, et al.; American College of Critical Care Medicine. Clinical practice guidelines for the management of pain, agitation, and delirium in adult patients in the intensive care unit. Crit Care Med. 2013;41(1):263-306.

2. Wunsch H, Kahn JM, Kramer AA, Rubenfield GD. Use of intravenous infusion sedation among mechanically ventilated patients in the United States. Crit Care Med. 2009;37(12):3031-9.

3. Kollef MH, Levy NT, Ahrens TS, Schaiff R, Prentice D, Sherman G. The use of continuous i.v. sedation is associated with prolongation of mechanical ventilation. Chest. 1998;114(2):541-8.

4. Dubois MJ, Bergeron N, Dumon M, Dial SM, Skrobik Y. Delirium in an intensive care unit: a study of risk factors. Intensive Care Med. 2001;27(8): 1297-304.

5. Ely EW, Shintani A, Truman B, SperoffT, Gordon SM, Harrell FE Jr, et al. Delirium as a predictor of mortality in mechanically ventilated patients in the intensive care unit. JAMA. 2004;291(14):1753-62.

6. Gerlach AT, Murphy CV, Dasta JF. An updated focused review of dexmedetomidine in adults. Ann Pharmacother. 2009;43(12):2064-74.

7. Dexmedetomidine. In: Repchinsky C, editor. Compendium of pharmaceuticals and specialties (e-CPS). Ottawa (ON): Canadian Pharmacists Association; [cited 2012 Jul 4]. Available from: https://www-e-therapeutics.ca.ezproxy. library.ubc.ca/cps.select.preliminaryFilter.action?simplePreliminaryFilter= dexmedetomidine $+\mathrm{HCl}$ (subscription required to access content).

8. Riker RR, Shehabi Y, Bokesch PM, Ceraso D, Wisemandle W, Koura F, et al.; SEDCOM (Safety and Efficacy of Dexmedetomidine Compared With Midazolam) Study Group. Dexmedetomidine vs midazolam for sedation of critically ill patients: a randomized trial. JAMA. 2009;301(5):489-99.

9. Pandharipande PP, Pun BT, Herr DL, Maze M, Girard TD, Miller RR, et al. Effect of sedation with dexmedetomidine vs lorazepam on acute brain dysfunction in mechanically ventilated patients: the MENDS randomized controlled trial. JAMA. 2007;298(22):2644-53.

10. Tan JA, Ho KM. Use of dexmedetomidine as a sedative and analgesic agent in critically ill adult patients: a meta-analysis. Intensive Care Med. 2010; 36(6):926-39.

11. Jakob SM, Ruokonen E, Grounds RM, Sarapohja T, Garratt C, Pocock SJ, et al. Dexmedetomidine vs midazolam or propofol for sedation during prolonged mechanical ventilation: two randomized controlled trials. JAMA. 2012;307(11):1151-60. 
Krystin Boyce, BSc, BSc(Pharm), ACPR, was, at the time this study was conducted, a Pharmacy Practice Resident with Lower Mainland Pharmacy Services, Vancouver, British Columbia. She is now a Clinical Pharmacist at Surrey Memorial Hospital, Surrey, British Columbia.

Edward C Dillon, BA, BSC, BSc(Pharm), RPh, ACPR, PharmD, is a Clinical Pharmacotherapy Specialist - Intensive Care, Surrey Memorial Hospital, Surrey, British Columbia.

Jerrold Perrott, BSC(Pharm), ACPR, PharmD, is a Clinical Pharmacy Specialist - Critical Care (ICU), Royal Columbian Hospital, New Westminster, British Columbia.

Douglas L Malyuk, BSc(Pharm), ACPR, PharmD, is a Clinical Pharmacy Specialist - Critical Care (ICU), Royal Columbian Hospital, New Westminster, British Columbia.

Vincent Mabasa, BSc(Pharm), ACPR, PharmD, is Coordinator of Clinical Pharmacy Services, Burnaby Hospital, Burnaby, British Columbia.

Emma Attfield is a student in the BSc(Pharm) program, Faculty of Pharmaceutical Sciences, University of British Columbia, Vancouver, British Columbia.
Grant McCormack, MD, FRCPC, was, at the time this study was conducted, Head of the Department of Intensive Care Medicine, Surrey Memorial Hospital, Surrey, British Columbia. He is currently a Respirologist and Intensivist practising at Surrey Memorial Hospital.

Sean Keenan, MD, FRCPC, is Head of the Department of Critical Care Medicine, Royal Columbian Hospital, Fraser Health Authority, New Westminster, British Columbia.

Competing interests: None declared.

\author{
Address correspondence to: \\ Krystin Boyce \\ Pharmacy Department \\ Surrey Memorial Hospital \\ 1375096 Avenue \\ Surrey BC V3V1Z2 \\ e-mail: krystin.boyce@fraserhealth.ca
}

